\title{
Ensino médio no Brasil: os desafios das políticas de garantia do direito a sua universalização
}

Eliza Bartolozzi Ferreira Universidade Federal do Espírito Santo

\section{Resumo}

Este texto objetiva tratar dos desafios do ensino médio. São apresentados os aspectos políticos e econômicos concernentes à democratização do ensino médio com apresentação de dados do atendimento da escolaridade no Brasil. Debate ainda a função social do ensino médio tendo em vista as políticas educativas atualmente implantadas. Conclui-se que os avanços legais e a implantação de programas educacionais voltados para a expansão do ensino médio têm gerado resultados pífios, fazendo crer que a universalização do ensino do ensino médio continuará sendo um desafio de longo prazo de superação.

Palavras-chave: Ensino médio. Políticas de educação. Educação básica. 


\section{Secondary education in Brazil: the challenges faced by the policies to assure and universalize this right}

This paper aims at addressing the challenges of secondary education. It presents political and economic aspects relative to the democratization of secondary education, including data on the coverage of Brazilian schools. It also debates the social function of secondary school, in view of educational policies currently implemented. Finally, it concludes that legal advances and the implementation of educational programs aimed at the expansion of secondary education have generated poor results, suggesting that the universalization of secondary education will remain a long-term challenge to overcome.

Keywords: High school education. Education policies. Basic education.

\section{Enseñanza Secundaria en Brasil: los desafíos de las políticas de garantía al derecho a su universalización}

Este texto tiene por objetivo tratar los desafíos de la enseñanza secundaria. Son presentados los aspectos políticos y económicos concernientes a la democratización de la enseñanza media, presentando datos de la atención escolar en Brasil. Debate también la función social de la enseñanza secundaria teniendo en consideración las políticas educativas actualmente implantadas. Se concluye que los avances legales y la implantación de programas educacionales volcados para la expansión de la enseñanza media han generado resultados mediocres, haciendo creer que la universalización de la enseñanza secundaria continuará siendo un desafío de superación a largo plazo.

Palabras clave: Escuela secundaria. Las políticas educativas. La educación básica. 


\section{Introdução}

0 debate sobre o ensino médio no Brasil deve ter como ponto de partida a análise de sua expressão conceitual e material. Isto é, importa compreender o ensino médio como etapa da educação básica e o que isso representa no processo de formação cidadã dos jovens brasileiros. Ademais, o ensino médio é uma fase da escolaridade do jovem que pode levá-lo a uma inserção laboral. Em seu aspecto legal, a educação básica preconizada pela Lei de Diretrizes e Bases da Educação Nacional (LDB - Lei 9.394/1996) é um nível escolar (a educação superior é o outro nível) constituído pelas etapas da educação infantil, ensino fundamental e ensino médio. Suas finalidades são desenvolver o educando, assegurar-lhe a formação comum indispensável para o exercício da cidadania e fornecer-lhe meios para progredir no trabalho e em estudos posteriores (art. 22). Além das etapas, a educação básica deve assegurar a integração de todas as modalidades de ensino (Educação de Jovens e Adultos, Educação Profissional, Educação Especial, Educação do Campo, Educação Indígena).

A análise de Cury (2002) é exemplar no que diz respeito ao significado posto pela LDB sobre a educação básica. Diz ele que

A educação básica é um conceito mais do que inovador para um país que por séculos, negou, de modo elitista e seletivo, a seus cidadãos o direito ao conhecimento pela ação sistemática da organização escolar. Resulta daí que a Educação Infantil é a base da Educação Básica, o Ensino Fundamental é o seu tronco e o Ensino Médio é seu acabamento, e é de uma visão do todo como base que se pode ter uma visão consequente das partes. A Educação Básica torna-se, dentro do art. $4^{\circ}$ da LDB, um direito do cidadão à educação e um dever do Estado em atendê-lo mediante oferta qualificada. E tal o é por ser indispensável, como direito social, a participação ativa e crítica do sujeito, dos grupos a que ele pertença, na definição de uma sociedade justa e democrática. (Cury, 2002, p.171-172).

Nosso ponto de partida é de que o ensino médio, como uma etapa efetivamente integrante da educação básica, tem o compromisso de compor um quadro formativo amplo e complexo de acordo com as diversidades, diferenças e desigualdades constituintes da história dos jovens brasileiros inseridos na sociedade pós-industrial. ${ }^{1}$

Concordamos com Kuenzer (2010) quando afirma que a incorporação de todas as modalidades de educação na concepção de educação básica, estabelecendo sua

1. Ferreira; Pochmann, 2011. 
integração e assegurando sua organicidade, decorre da concepção de educação como totalidade. Isso significa organizar a educação básica como um sistema que não admite formas paralelas que comprometam a assumida integração entre as etapas e modalidades de ensino oferecidas pela educação escolar e as demais ações educativas que ocorrem no conjunto das práticas sociais. Assegura, dessa forma, tanto a organicidade interna à educação básica, quanto a externa, articulando, pela mediação da educação, conhecimento, trabalho e cultura.

A discussão sobre o ensino médio, e a literatura da área revela isso, aponta alguns consensos os quais orientam as análises, sendo determinante a noção de que há um difícil equacionamento na configuração da identidade do ensino médio porque esteve sempre dividido entre oferecer um ensino profissionalizante com caráter de terminalidade ou oferecer um ensino propedêutico voltado ao prosseguimento dos estudos em nível superior. Com a promulgação da LDB/1996, o ensino médio assumiu a condição de uma etapa da educação básica, a terceira e última, com a responsabilidade de consolidar e aprofundar os conhecimentos adquiridos no ensino fundamental para prosseguimento dos estudos; dar uma preparação básica para o trabalho e para a cidadania, com desenvolvimento da autonomia intelectual e do pensamento crítico, aliando teoria e prática. De acordo com Cury (2002), do ponto de vista legal, o ensino médio não é nem porta para o ensino superior e nem chave para o mercado de trabalho, embora seja requisito tanto para a graduação superior quanto para a profissionalização técnica.

Ainda do ponto de vista dos marcos legais, destacamos avanços conquistados recentemente na perspectiva do ensino médio como direito à educação básica, são eles: a Lei $n^{0} 12.061$, de 27 de outubro de 2009, que alterou o inciso II do art. $4^{\circ}$ e o inciso VI do art. 10 da Lei no 9.394/96, para assegurar o acesso de todos os interessados ao ensino médio público. 0 que antes era dever de assegurar uma progressiva extensão da obrigatoriedade e gratuidade ao ensino médio torna-se, com a nova lei, o dever do Estado de assegurar a universalização do ensino médio gratuito. A Emenda Constitucional $n^{0} 59$, de 11 de novembro de 2009 - que acrescenta $0 \leq 3^{\circ}$ ao art. 76 do Ato das Disposições Constitucionais Transitórias para reduzir, anualmente, a partir do exercício de 2009, o percentual da Desvinculação das Receitas da União (DRU) incidente sobre os recursos destinados à manutenção e desenvolvimento do ensino de que trata o art. 212 da Constituição Federal - dá nova redação aos incisos I e VII do art. 208, de forma a prever a obrigatoriedade do ensino de quatro a dezessete anos e ampliar a abrangência dos programas suplementares para todas as etapas da educação básica, e dá nova redação ao $\leq 4^{\circ}$ do art. 211 e ao $\leq 3^{\circ}$ do art. 212 e ao caput do art. 214 , com a inserção neste dispositivo de inciso VI. 
Essa nova legislação propõe a universalização do ensino médio e busca garantir recursos ao desvincular a DRU², aumentando os recursos financeiros da educação. Assegurar a educação básica obrigatória e gratuita dos 4 (quatro) aos 17 (dezessete) anos de idade, inclusive sua oferta gratuita para todos os que a ela não tiveram acesso na idade própria, "remete não só à universalização, mas ao tratamento integrado do trajeto curricular a ser percorrido da educação infantil ao ensino médio" (Kuenzer, 2010, p. 854) e isso exige do poder público a promoção das condições objetivas e, sobretudo, de uma articulação dos sistemas estaduais de educação em torno de um sistema nacional ainda por se organizar.

Assim, garantir o ensino médio no Brasil sob a perspectiva de uma expansão democrática com qualidade torna-se um desafio político de difícil enfrentamento, tanto do ponto de vista de seus sujeitos que, sendo jovens, guardam uma particularidade geracional e, consequentemente, cultural; quanto ao fato de a oferta dessa etapa de ensino ser de responsabilidade direta dos estados regionais. Ademais, a complexidade aumenta quando remetemos aos problemas históricos vividos pelo ensino médio ao longo de sua constituição, cujo crescimento, na década de 1970, deu-se predominantemente com matrículas no ensino noturno, indicando que os jovens em busca da escola são trabalhadores. Ou seja, as escolas de ensino médio são ocupadas, sobretudo, por trabalhadores ou por aqueles que procuram emprego.

Este texto objetiva tratar dos desafios do ensino médio, considerados uma etapa da educação básica para todos os brasileiros dentro do contexto atual de aumento da demanda pela escolarização por parte da sociedade civil e política, combinada com uma necessidade de que esta oferta seja realizada com qualidade. Na primeira parte do texto, o objetivo é tratar dos aspectos políticos e econômicos concernentes à democratização do acesso do ensino médio com apresentação de dados reveladores do atendimento da escolaridade no Brasil, para depois, no segundo momento, discorrer sobre a função social cumprida pelo ensino médio tendo em vista as políticas educativas implantadas para essa etapa de ensino nos últimos anos.

2. Criada em 1994 com o nome de Fundo Social de Emergência, a DRU permite à União retirar da área educacional $20 \%$ dos recursos que, pela Constituição Federal, teriam que ser destinados ao setor. A partir da referida Emenda, a alíquota que era de 20\% cai para 12,5\% no exercício de 2009 e 5\% em 2010, até que em 2011 não haverá mais a incidência da DRU na educação (Oliveira, 2010, p. 6). 


\section{0 ensino médio em busca de uma identidade}

Se o objetivo deste texto é traçar um quadro analítico para compreender as políticas do ensino médio no Brasil, é prudente que se estabeleça como limite temporal os acontecimentos iniciados na década de 1990. Desse modo, o principal marco legal da reforma do ensino médio no Brasil é a LDB, que colocou a escola média como uma etapa da educação básica com os objetivos de aprofundar os conhecimentos adquiridos no ensino fundamental, possibilitando o prosseguimento dos estudos na educação superior e, ao mesmo tempo, garantindo a preparação básica para o trabalho e para o exercício da cidadania.

Em 1998, o Conselho Nacional de Educação (CNE) estabeleceu as Diretrizes Curriculares Nacionais para o Ensino Médio (Resolução CEB/CNE n 03/98). Em linhas gerais, as novas diretrizes curriculares foram elaboradas em consonância com as posições de alguns dos principais textos internacionais sobre educação do período, o Relatório Delors (2001) - A educação encerra um tesouro - e o texto da CEPAL - Educación y conocimiento: eje de la transformación productiva com equidad (CEPAL, 1992). Ou seja, a reforma curricular do ensino médio é parte integrante das políticas educacionais propostas pelo governo Cardoso (1995-2002), que por sua vez expressavam uma concepção de educação orgânica ao modelo econômico hegemônico no processo globalizado de acumulação flexível.

Outro marco definidor da reforma educativa empreendida na década de 1990 foi a edição do Decreto $n^{0}$ 2.208/1997. Com esse decreto, o ensino médio assumiu um caráter propedêutico, pois ficou proibida a sua oferta junto com uma preparação básica para o trabalho na medida em que instituiu a oferta do ensino médio separada da oferta dos cursos de educação profissional. Esse fato aprofundou a crise de identidade do ensino médio, mas, sobretudo, forçou os alunos das classes populares, geralmente trabalhadores, a ficarem mais tempo em escolas estruturalmente precárias tanto física quanto pedagogicamente. 0 resultado dessa política pôde ser observado na expansão da oferta de cursos profissionalizantes no setor privado e no enfraquecimento do ensino médio combinado com o fracasso do Programa de Expansão da Educação Profissional (PROEP) levado a cabo pelo MEC, que não atingiu o objetivo proposto e explícito no nome do programa.

0 Decreto $n^{0} 2.208 / 97$ impactou a educação dos jovens brasileiros em um momento de grande efervescência no mercado de trabalho, pautado pelo desemprego e pela busca da qualificação profissional. Somente em 2004, com a edição de um novo decreto (Decreto $n^{0} 5.154 / 2004$ ), houve um retorno a possibilidade da oferta integrada da formação geral e específica pelas escolas de ensino médio do país, mas observamos 
uma difícil recuperação, tendo em vista a tradicional heterogeneidade e fragilidade dessa etapa de ensino no conjunto da escolaridade do jovem brasileiro agravada pelas incertezas e pela sociedade de risco (Beck, 2003).

\section{As implicações da política governamental no ensino médio}

No interior da discussão sobre o ensino médio, entendemos como necessário situar a conjuntura histórica atual como uma reflexão sobre o cenário no qual são tecidas as tramas que dimensionam as diversas correlações de forças que orientam as políticas educativas no plano teórico e da prática social. Isso porque partimos do princípio de que as transformações vividas pela sociedade capitalista brasileira, pelo menos nos últimos 30 anos, determinaram novos alinhamentos políticos, jurídicos, econômicos e culturais impactantes na organização do trabalho como um todo e, especificamente, no campo da educação escolar.

Um exame, mesmo que sumário, dos oito anos do governo Lula (2003-2010) não pode prescindir de um retorno aos anos que o precederam, pois além da necessária visão da história como processo, os anos vividos no governo Cardoso (1995-2002) foram determinantes na orientação da economia e do campo da educação escolar. Nesse governo tomado pelo neoliberalismo, observamos o surgimento de novas experiências com o fenômeno da privatização, da dissolução de direitos, da desregulação da produção e da volatilidade da economia, deixando um quadro de altas taxas de desemprego, de informalidade e de precarização do trabalho de grande parte da população.

No último quartel do século XX, o mundo capitalista passou por profundas transformações políticas, econômicas, jurídicas, laborais e tecnológicas que levaram ao surgimento da sociedade pós-industrial com o predomínio do setor de serviços sobre a industrialização. Isto é, observou-se uma tendência das forças produtivas à desindustrialização e, paralelamente, houve o crescimento do setor de serviços. A reestruturação do sistema capitalista e o impacto de tais alterações na condição de emprego de grande parte da população, com forte impacto na organização do trabalho, fez com que novas demandas de formação e qualificação fossem orquestradas pela classe empresarial e política (Pochmann, 2010).

Com o reconhecimento do caráter parcial e de nossas limitações para interpretar uma realidade social tão complexa como a brasileira, sinalizaremos alguns pontos que consideramos necessários para análise da política para o ensino médio na conjuntura política e econômica do século XXI. Podemos observar práticas congruentes e incongruentes nos projetos políticos empreendidos nesses dezesseis anos de gestão do 
Estado brasileiro, as quais impactaram em diferentes medidas na estruturação do ensino médio.

Podemos afirmar que o período do governo Lula é marcado por diferentes nuances entre o primeiro e o segundo mandato. No primeiro mandato (2003-2006), segundo análise feita em outro momento (Ferreira, 2010) sobre o planejamento da educação profissional nos PPAs, constatamos a opção do governo Lula pela forma conciliatória de tratar dos problemas estruturais da sociedade brasileira, em que pese a relevância do fato de articular uma extensa agenda de debates com a sociedade civil a respeito dos problemas sociais, especialmente no que tange ao ensino médio e educação profissional. A avaliação comparativa realizada com os PPAs do governo Cardoso levounos a verificar um avanço nas políticas de gestão da Educação Profissional realizado pelo governo Lula, mas esse avanço foi considerado tímido, principalmente quando remetemos aos recorrentes contingenciamentos de recursos financeiros, os quais emperraram o cumprimento das metas e revelaram a prioridade política do governo Lula pelo atendimento aos compromissos do mercado internacional.

De acordo com a análise de Barbosa e Souza (2010), há um predomínio de duas vertentes ideológicas no interior do governo Lula: uma visão neoliberal e outra desenvolvimentista, sendo que no primeiro mandato houve o predomínio da visão neoliberal.

No campo prático das ações do governo Lula, a visão neoliberal se refletiu em uma posição conservadora sobre o potencial de crescimento da economia em 2003-2005. Sua consequência imediata foi recomendar uma estratégia de forte contenção fiscal para abrir espaço ao crescimento limitado e o mercado é sempre mais eficiente do que o governo, de tal modo que a única forma de acelerar o desenvolvimento é liberalizar a economia, cortar impostos e conter os gastos públicos. (Barbosa e Souza, 2010, p. 68).

Na visão dos desenvolvimentistas organizados no interior do governo Lula, segundo os autores supracitados, o principal instrumento de atuação do Estado era a elevação do valor real do salário mínimo. Ademais, os aumentos de transferências de renda puderam ser implementados sem gerar desequilíbrios fiscais. Ou seja, os desenvolvimentistas enfatizavam uma postura mais ativa do Estado na promoção do desenvolvimento brasileiro. Em 2006, o governo Lula optou pelo modelo desenvolvimentista: "Três iniciativas tomadas na execução da política fiscal, ainda em 2006, marcaram a inflexão econômica: elevação substancial do salário mínimo, do aumento do investimento público e reestruturação de carreiras e salários dos servidores públicos" (Barbosa e Souza, 2010, p. 74).

No segundo mandato, em 2007, a adoção do Programa de Aceleração do Crescimento (PAC) recuperou a capacidade de induzir o desenvolvimento de amplo espectro 
de setores fundamentais para a modernização da economia. "A estratégia do governo, pela primeira vez em muitas décadas, foi apoiar a formação de capital da parte do setor privado e, simultaneamente, aumentar o investimento público em infraestrututra" (Barbosa e Souza, 2010, p. 75-76).

Filgueiras e Gonçalves (2007) entendem que o governo Lula manteve a política macroeconômica do governo Cardoso, pautada no modelo liberal periférico. Tal modelo tem três conjuntos de características marcantes: liberalização, privatização e desregulação; subordinação e vulnerabilidade externa estrutural; e dominância do capital financeiro. Os autores consideram que o primeiro governo Lula manteve a mesma política econômica do segundo mandato do governo Cardoso, caracterizado por metas de inflação, ajuste fiscal permanente e câmbio flutuante.

No que diz respeito à política social do governo Lula, os autores argumentam que essa política tem estreita relação com a política econômica liberal-ortodoxa, legado do governo anterior como uma herança maldita, mas mantida e aprofundada pelo governo Lula. Como crítica à política social do governo Lula de focalização aos mais pobres, os autores destacam que a política focalizada é de natureza mercantil e tratase de uma operação ideológica de despolitização do conflito distributivo. "Concebe a redução da pobreza como um 'bom negócio' e transforma o cidadão portador de direitos e deveres sociais em um consumidor tutelado, por meio de transferência direta de renda" (Filgueiras e Gonçalves, 2007, p. 156).

Nos marcos do capitalismo globalizado, as dinâmicas políticas e econômicas dos governos brasileiros que administram o Estado neste século XXI têm como base a contradição e a busca de mecanismos de regulação que ordenem, controlem e equilibrem minimamente a questão social, sendo a desigualdade e a pobreza os aspectos mais desafiadores. Nesse sentido, a educação é um campo de adensamento de diversos problemas sociais, geralmente percebido como solução de muitos deles, especialmente no sentido da promoção da empregabilidade.

\section{0 que dizem os dados estatísticos sobre a realidade do ensino médio}

Os desafios apresentados para a sociedade e para o Estado são novos e mais complexos, carregados de uma herança de dificuldades de inserção de grande contingente populacional. Em um contexto de transformações significativas das trajetórias do mundo do trabalho e da cultura do trabalho nos novos processos produtivos, aprofundadas pela destruição de empregos e da crescente flexibilidade e informalidade do trabalho, os dados das condições da população brasileira apresentados pela Pesquisa 
Brasileira por Amostra de Domicílios (PNAD/IBGE) de 2009 são preocupantes e nos mobilizam a pensar sobre o direito a educação básica no Brasil, particularmente o ensino médio.

De acordo com o relatório da PNAD/IBGE 2009, a população brasileira residente foi estimada em 191,8 milhões. Em todos os grupamentos de idade compreendidos por pessoas de 0 a 24 anos foi observada redução da participação na população residente em relação a 2008. A estrutura etária da população residente continua apresentando tendência de envelhecimento, com aumento na participação da população nas idades mais altas e redução nas idades mais jovens. Enquanto na população de 0 a 24 anos de idade houve redução de 642 mil pessoas, entre aquelas na faixa etária de 25 a 59 anos o aumento do contingente foi de 1,8 milhão de pessoas. Na população de 60 anos ou mais de idade, o crescimento foi de 697 mil pessoas, de 2008 para 2009, o que representou um aumento de 3,3\%, contra uma elevação de 1,0\% no total da população residente do país. A mudança demográfica no Brasil aponta para a necessidade de cuidar da herança deixada por aqueles que ainda não conseguiram se inserir no processo educativo de forma a cumprir com a escolaridade de 13 anos (pois a obrigatoriedade ocupa a faixa etária de 4 a 17 anos de idade), ao mesmo tempo em que exige a definição de políticas para o atendimento à população mais velha.

Em relação à faixa etária de 6 a 14 anos de idade, a taxa de escolarização foi de $97,6 \%$ em 2009, um aumento de 1,5 ponto percentual em relação a 2004. Para os jovens de 15 a 17 anos de idade, a proporção dos que frequentavam a escola foi de 85,2\%. Um indicador que qualifica melhor a situação educacional dessa faixa etária é a taxa de frequência líquida, que reflete a adequação idade/nível de ensino cursado, a qual ficou em $48 \%$ dos adolescentes nessa faixa etária que cursaram o ensino médio em 2007.

Ao se observar a escolarização segundo as classes de rendimento mensal domiciliar per capita, verificou-se que $96,5 \%$ das crianças de 6 a 14 anos de idade que residiam em domicílios com rendimento mensal domiciliar per capita inferior a 1/4 do salário mínimo frequentavam a escola, proporção esta que aumenta consoante o aumento do rendimento. Os domicílios com rendimento mensal domiciliar per capita de um salário mínimo ou mais apresentaram $99,0 \%$ das crianças de 6 a 14 anos de idade frequentando a escola. Em todas as regiões do Brasil, a proporção de crianças de 6 a 14 anos de idade que frequentavam a escola foi superior a $96 \%$. Portanto, a universalização do atendimento do Ensino Fundamental esbarra na condição social das famílias, e mesmo com a expansão das políticas assistencialistas nos últimos anos esse quadro tem dificuldades de se alterar.

Com relação à população jovem de 15 a 24 anos de idade, o Brasil apresenta uma taxa de analfabetismo residual de 2,4\%. Em 2007, a PNAD revelou que 5,3\% se encontravam 
nesta situação, o que mostra uma redução significativa. Observamos uma melhora do nível de escolaridade no Brasil ao verificar a distribuição das pessoas de 25 anos ou mais de idade segundo o nível de instrução: a proporção daquelas com nível superior completo aumentou 2,5 pontos percentuais de 2004 para 2009, alcançando $10,6 \%$, e a proporção das que possuíam somente o nível médio completo passou de $18,4 \%$, em 2004, para $23,0 \%$ em 2009 , representando um aumento de $4,6 \%$ no período.

Dos jovens entre 18 e 24 anos de idade, apenas 30,9\% informaram que frequentavam escola ou universidade. Nesta faixa etária, pelos critérios de adequação idade/nível de ensino, esses jovens deveriam estar cursando a universidade. No entanto, 57,6\% estavam cursando o ensino fundamental, médio ou outros (pré-vestibular, supletivo e alfabetização de adultos), e 42,4\% estavam cursando cursos de graduação ou pós-graduação.

No conjunto da população brasileira de 15 anos ou mais de idade, a escolaridade média em 2007 ainda não havia alcançado um nível satisfatório, apenas 7,3 anos de estudo. Houve um aumento nesta média de 1,5 anos de estudo em relação a 1997, quando o valor encontrado era de 5,8 anos. Os ganhos na escolaridade média da população têm sido indiscutivelmente lentos. As diferenças entre as áreas urbana e rural são extremamente marcantes, sendo a média para o setor rural de apenas 4,5 anos, enquanto a urbana é de 7,8 anos.

De acordo com as análises de dados contidas na Síntese dos Indicadores Sociais do IBGE, uma análise das condições de vida da população brasileira (IBGE, 2010), a taxa de escolarização líquida, analisada pelos quintos do rendimento mensal familiar per capita, revela fortes desigualdades entre os mais pobres e os mais ricos: no primeiro quinto los $20 \%$ mais pobres), somente $32,0 \%$ dos adolescentes de 15 a 17 anos de idade estavam no ensino médio, enquanto no último quinto ( $20 \%$ mais ricos) essa oportunidade atingia quase $78 \%$ do grupo, revelando que a renda familiar exerce grande influência na adequação idade/série frequentada.

0 Censo Escolar 2010 (INEP) apresenta dados sobre a oferta escolar para a população brasileira. Nos 194.939 estabelecimentos de educação básica do país estão matriculados 51.549 .889 alunos, sendo que 43.989 .507 (85,4\%) estão em escolas públicas e $7.560 .382(14,6 \%)$ em escolas da rede privada. As redes municipais são responsáveis por quase metade das matrículas - 46,0\% - o equivalente a 23.722 .411 estudantes, seguidas pela rede estadual, que atende a $38,9 \%$ do total, o equivalente a 20.031.988. A rede federal, com 235.108 matrículas, participa com $0,5 \%$ do total. Houve uma queda de 2,8\% nas matrículas da rede pública em relação a 2009. Em contrapartida, a rede privada cresceu $3,4 \%$. Ainda comparando as matrículas nas dependências administrativas, cabe destacar o crescimento de $8,0 \%$ na rede federal, o maior crescimento se comparado às demais redes. 
Registra-se, também, estabilidade na oferta de ensino médio, com aumento de 20.515 matrículas em 2010, totalizando 8.357 .675 matrículas, correspondendo a $0,2 \%$ a mais que em 2009. A rede estadual é a maior responsável pela oferta de ensino médio e responde por $85,9 \%$ das matrículas. A rede privada atende a $11,8 \%$ e as redes federal e municipal atendem a pouco mais de $1 \%$ cada.

A educação de jovens e adultos (EJA) apresentou queda de 5,0\% (374.098), totalizando 4.234.956 matrículas em 2010. Desse total, 2.846.104 (67\%) estão no ensino fundamental e 1.388.852 (33\%) no ensino médio. Segundo dados da Pnad/IBGE 2009, o Brasil tem uma população de 57,7 milhões de pessoas com mais de 18 anos que não frequenta escola e que não tem o ensino fundamental completo. Esse contingente poderia ser considerado uma parcela da população a ser atendida pela EJA.

A maioria da matrícula de EJA está na rede pública, distribuída da seguinte forma: $54,8 \%$ na rede estadual, $41,7 \%$ na rede municipal e $0,4 \%$ na rede federal, cabendo à rede privada uma participação de 3,1\%. Merece destaque também a integração da EJA com a educação profissional. A educação de jovens e adultos de ensino fundamental, associada à formação profissional totaliza 14.126 matrículas, e as de ensino médio são 38.152. Esses números indicam que há espaço para ampliação da oferta de EJA integrada à educação profissional.

A análise do ensino médio não pode prescindir de situar a diversidade de sujeitos que buscam e precisam dele, e esse é o fator predominante na definição do que significa esta etapa da educação básica na vida dessas pessoas. Mas a crise do ensino médio não pode ser remetida tão somente à dificuldade na definição de sua identidade, mas deve também ser vinculada a uma crise da educação como um todo e da sociedade. ${ }^{3}$ Em estudo de Ferreira e Pochmann (2011), foi destacada a situação dos jovens em relação ao processo educacional. Dos 29,3 milhões de jovens na faixa de 16 a 24 anos de idade, somente 12,1 milhões $(41,3 \%)$ estudavam em 2008. Deste universo, 46,3\% (5,6 milhões) não trabalhavam e nem procuravam trabalho (inativos), 43,8\% (5,3 milhões) estavam ocupados e $9,9 \%$ (1,2 milhão) desempregados. Em relação aos jovens que não frequentavam a escola (17,2 milhões), 66,7\% trabalhavam (11,4 milhões), 22,8\% não trabalhavam e nem procuravam trabalho (3,9 milhões) e 10,5\% estavam desempregados (1,8 milhões).

Com base nesses dados, a procura pelo ensino médio, por mais que tenha crescido nos últimos anos em decorrência do aumento da oferta do ensino fundamental adicionado pelas exigências do mercado de trabalho, não parece ser uma via de fácil acesso

3. Ver Ferreira e Oliveira, 2009. 
e permanência. Vários são os fatores que contribuem para isso: a precariedade física e tecnológica das escolas públicas; professores desmotivados e insatisfeitos com seus salários; uma intensificação do trabalho docente em face das novas atividades e de problemas sociais enfrentados no interior da escola; um currículo estático e instrumentalista; ausência da cultura e da participação da juventude sobre os rumos da sociedade e da escola; crise do papel da escola como formadora para um emprego que se torna escasso etc.

Até a promulgação da Lei nº 12.061/2009, o ensino médio não tinha caráter obrigatório e ficou em uma posição secundária no âmbito da política educacional do Ministério da Educação (MEC). Mesmo assim, o acesso ao ensino médio sofreu forte expansão ao longo do período 1988-2007, com taxa de crescimento de 219\% (IPEA, 2009), uma tendência mobilizada pela pressão do aumento do acesso ao ensino fundamental e pelas próprias exigências do mercado de trabalho. Mas a taxa de frequência líquida no ensino médio é ainda muito baixa, ficando em torno de $48 \%$. Assim, a nova lei propõe um grande desafio para a sociedade brasileira na luta pelo direito à educação básica no país.

Considerando que somente $48 \%$ dos jovens entre 15 e 17 anos estão cursando o ensino médio; considerando ainda que dos jovens entre 18 e 24 anos de idade apenas $30,9 \%$ frequentam escola ou universidade; e considerando que uma parte significativa desses jovens está matriculada no turno noturno, a promoção da expansão da escola de ensino médio é uma empreitada que envolve muitas variáveis, estratégias de ação política e de condições objetivas de variados graus e amplitudes, tendo em vista a pobreza social e dificuldades de acesso à cultura da maioria da juventude brasileira.

Para citar um exemplo da complexidade que temos pela frente, uma leitura dos dados da pesquisa de Souza, Portela e Lopes (2006), realizada no período de 2003/2006 com escolas consideradas de qualidade em sete estados brasileiros, mostra que, para os alunos, a escola "é, quase sempre, o único ou o principal espaço público de acesso à informação e à cultura sistematizada". Os profissionais das escolas de ensino médio também apresentaram um restrito acesso aos bens culturais. Outro dado revelador da problemática a ser enfrentada para a universalização do ensino médio é apresentado nas respostas de alunos e alunas quando consultados sobre quais motivos seriam decisivos para que se ausentassem das aulas: cansaço, compromissos profissionais, falta de transporte, desinteresse por matérias e falta de afinidade com os professores. Portanto, a problemática envolve questões extra e intraescolares. Em relação à antiga tensão sobre a identidade do ensino médio, praticamente todos os entrevistados nessa pesquisa (professores, diretores, coordenadores pedagógicos e alunos) afirmaram que o ensino médio deve oferecer formação geral e profissional. 
A categoria trabalho é incorporada tanto pela legislação como pelas representações dos sujeitos que vivem do ensino médio, mas o grande desafio está em entender e situar a dimensão do trabalho no currículo do ensino médio de modo que seja uma condição de emancipação política, e não uma validação do processo de alienação ao se limitar ao atendimento ao emprego strictu senso ou à empregabilidade.

As Diretrizes Curriculares para a Educação Básica definidas pela Resolução CEB/CNE n 4 de 13 de julho de 2010 propõem a visão do conjunto orgânico, sequencial e articulado das etapas e modalidades da educação básica. 0 art. 26 trata especificamente do ensino médio e, ao assegurar os princípios da LDB, apresenta os seguintes parágrafos:

§ $1^{\circ} 0$ Ensino Médio deve ter uma base unitária sobre a qual podem se assentar possibilidades diversas como preparação geral para o trabalho ou, facultativamente, para profissões técnicas; na ciência e na tecnologia, como iniciação científica e tecnológica; na cultura, como ampliação da formação cultural.

$\S 2^{\circ} \mathrm{A}$ definição e a gestão do currículo inscrevem-se em uma lógica que se dirige aos jovens, considerando suas singularidades, que se situam em um tempo determinado. $\S 3^{\circ}$ Os sistemas educativos devem prever currículos flexíveis, com diferentes alternativas, para que os jovens tenham a oportunidade de escolher o percurso formativo que atenda seus interesses, necessidades e aspirações, para que se assegure a permanência dos jovens na escola, com proveito, até a conclusão da Educação Básica.

Observa-se que tais diretrizes trazem preocupação com a integração da formação geral à preparação para profissões técnicas. A partir dessa proposta teórico-metodológica, podemos observar alguns programas criados para o ensino médio antes mesmo da promulgação dessas diretrizes. Um deles é o programa Ensino Médio Inovador, instituído pela Portaria Federal no 971/2009, com o objetivo de apoiar e fortalecer os sistemas estaduais de educação na adoção de propostas curriculares inovadoras nas escolas de ensino médio não-profissionalizantes. 0 programa pretende superar a dicotomia entre ensino profissionalizante e ensino propedêutico a partir da diretriz de que o trabalho é um princípio educativo e deve mediar o processo pedagógico, superando o limite do imediato e do utilitarismo do mercado. Portanto, a escola do ensino médio deve tratar do trabalho sem necessariamente ser profissionalizante. Para tanto, o programa propõe apoiar financeiramente e fortalecer a gestão da escola, a formação dos professores e a participação e protagonismo dos alunos por meio da instalação de fóruns.

A possibilidade de execução desse programa de forma ampliada e com resultados significativos dentro da totalidade do ensino médio no Brasil é muito limitada. Sem entrar nos detalhes que envolvem a complexidade das ações tanto no âmbito financeiro 
quanto no burocrático, que permeiam as relações entre os entes federativos, podemos citar dois elementos-base para análise da exequibilidade de tal programa: i) os estados federativos precisam incorporar a proposta e torná-la uma política de estado; ii) é sabido que a superação da dualidade discutida no programa depende da superação da estrutura de nossa sociedade capitalista, como bem já alertou Kuenzer:

[...] a superação da dualidade estrutural não é uma questão pedagógica, uma vez que é socialmente determinada pela contradição entre capital e trabalho. Ou seja, a divisão entre trabalho intelectual e trabalho prático, que por muito tempo justificou duas redes de ensino médio, uma de educação geral para a burguesia e outra profissional para os trabalhadores, tem sua origem na separação entre a propriedade dos meios de produção e a propriedade do trabalho. (Kuenzer, 2010, p. 862).

Sendo assim, a qualidade do trabalho da educação escolar e sua democratização dependem fundamentalmente de fatores exógenos à escola, o que, por sua vez, exige um plano de desenvolvimento social e econômico compatível com a emancipação da nação e de seus cidadãos. Pelo visto anteriormente, os governos Cardoso e Lula não tiveram essa coerência e nem mesmo um modelo de desenvolvimento coeso com as aspirações de autonomia nacional política e econômica.

O Programa de Ensino Médio Integrado e o Programa Nacional de Integração da Educação Profissional com a educação básica na modalidade Educação de Jovens e Adultos (PROEJA) são programas que visam a oferta de uma formação geral integrada a uma formação técnica. Tais programas foram viabilizados a partir do Decreto $\mathrm{n}^{0}$ 5.154/2004 e vem crescendo de forma lenta, na medida em que os sistemas estaduais e os institutos federais os inserem em sua gestão. De acordo com os dados do Censo Escolar (INEP, 2010), citados anteriormente, o Proeja totaliza hoje 38.152 matrículas e, em 2009, de acordo com dados do INEP, o Ensino Médio Integrado teve 175.831 alunos matriculados. Conferimos que é um número pouco expressivo, tendo em vista a totalidade de alunos matriculados no ensino médio em 2009, na ordem de 8.337.160 matrículas. Portanto, a perspectiva de unitariedade ainda está mais no discurso dos elaboradores das políticas educativas do que precisamente configurando uma prática pedagógica.

Por sua vez, vale destacar que as políticas educacionais dirigidas pelo MEC têm obtido números mais expressivos de atendimento a educação profissional ${ }^{4}$, com um

4. Atua na educação profissional um conjunto de estabelecimentos públicos e privados, que se caracterizam como escolas técnicas, agrotécnicas, centros de formação profissional, associações/escolas, dentre outros. 0 Censo Escolar 2010 revela que a participação da rede pública tem crescido anualmente e já representa $52 \%$ das matrículas. 
crescimento de 7,4\%, ultrapassando 900 mil matrículas em 2010. Considerando o Ensino Médio Integrado, os números indicam um contingente de 1,14 milhão de alunos atendidos. A educação profissional subsequente - oferecida aos alunos que já concluíram o ensino médio - aumentou $27 \%$ no número de matrículas e tem uma participação de $62 \%$ no total de matrículas da educação profissional. Por outro lado, na rede federal, a educação profissional concomitante ou integrada ao ensino médio tem uma participação de $61,8 \%$ do total de matrículas nesta rede. Nos últimos oito anos, a rede federal mais que dobrou a oferta de matrícula de educação profissional, com um crescimento de $114 \%$ no período.

0 crescimento da oferta da educação profissional revela a perspectiva do governo de vincular a questão social do emprego/desemprego como um problema de qualificação do trabalhador, independentemente da natureza e da quantidade dos postos de trabalho gerados pelo mundo produtivo. A presidente Dilma Roussef reforça essa tendência ao criar recentemente o Programa Nacional de Acesso ao Ensino Técnico e Emprego (Pronatec) com o objetivo de expandir, interiorizar e democratizar a oferta de cursos técnicos e profissionais de nível médio, e de cursos de formação inicial e continuada para trabalhadores. A medida visa intensificar o programa de expansão de escolas técnicas em todo o país, destinando bolsas-formação para os estudantes e trabalhadores, com recursos do orçamento do Ministério da Educação, do Fundo de Amparo ao Trabalhador (FAT), do Sistema S e do Banco Nacional de Desenvolvimento Econômico e Social (BNDES). Destacamos que a criação desse programa viabiliza o investimento público em setores privados da educação.

Chama atenção a relação linear estabelecida pelo governo entre educação e emprego sem a devida observância aos dados produzidos por instância desse mesmo governo. O IPEA (2011) informou que haverá um excedente de um milhão na força de trabalho qualificada e com experiência no Brasil, pois apresentamos uma oferta de 21 milhões de postos de trabalho e 22,1 milhões de pessoas com qualificação e experiência profissional. Isso porque a expansão econômica esperada para 2011 é menor que a de 2010, em que pese o fato de que os sinais de escassez de mão de obra qualificada e com experiência profissional deverão continuar se manifestando, cada vez em maior escala, mas em setores econômicos específicos e em determinadas localidades do país. Esses dados apenas confirmam que o projeto de educação para o país precisa extrapolar a visão utilitarista e caminhar em direção a uma escola que incorpore de forma dinâmica e orgânica os sujeitos em formação para uma sociedade livre e destituída dos valores capitalistas.

0 Projeto de Lei do Plano Nacional de Educação (PNE) para o decênio 2011-2020 em trâmite no Congresso Nacional aponta metas que buscam a expansão da oferta do 
ensino médio e da educação de jovens e adultos (Metas 3, 4, 8 e 10), fazendo uso de estratégias de fomento do currículo, de materiais didáticos etc., com destaque para a integração da formação geral com a técnica. Kuenzer (2010), em análise sobre o ensino médio no novo Plano Nacional de Educação, conclui que o grande desafio do PNE 20112020 é conferir materialidade ao discurso da educação básica como direito de todos e responsabilidade do Estado, mediante a institucionalização do Sistema Nacional de Educação como instância integradora dos esforços pela democratização da oferta de ensino médio com qualidade. Para tanto, o PNE deverá definir claramente a diretriz indicativa para os investimentos e para as ações, reposicionando, mediante a prática colaborativa entre os poderes públicos, a ação pública estatal, uma vez que há evidências empíricas a comprovar que a pulverização de recursos, ou seu repasse para que instituições privadas respondam pelas obrigações do Estado mediante programas pretensamente afirmativos, não tem apresentado efetividade social no sentido de impactar positivamente os indicadores de escolaridade, emprego e renda.

A legislação e os planejamentos para o ensino médio no Brasil apontam para a direção de sua democratização com base na unitariedade curricular, pelo menos no que diz respeito a integração da formação geral com a técnica. A adoção de uma estrutura curricular unitária pressupõe a formação de professores sob novas bases que não são as atualmente dadas pelas instâncias de formação inicial e continuada, como exemplo maior, a formação desenvolvida pelo ensino superior público e privado.

Em pesquisa realizada nos anos de 2009 e 2010, sob coordenação da Faculdade de Educação da Universidade Federal de Minas Gerais (FAE/UFMG), investigamos o perfil e as condições dos trabalhadores docentes na educação básica no Brasil, a qual envolveu sete estados (ES, GO, MG, RN, SC, PR, PA). Alguns dados valem ser destacados aqui como sinalização dos desafios para a melhoria da qualidade do ensino médio. Dos trabalhadores do ensino médio entrevistados, 95, 2\% têm formação de curso superior, sendo que 60,6\% têm pós-graduação. São 58\% de trabalhadores com graduação obtida em instituição pública de ensino superior e $67 \%$ são professores permanentes, mas cerca de $60 \%$ dos entrevistados trabalham em mais de uma instituição de ensino. A maioria recebe entre dois a quatro salários mínimos e 90\% afirmaram cumprir uma carga horária de trabalho extensa em casa.

Esses dados confirmam que os professores que atuam no ensino médio no Brasil têm uma formação considerada adequada, todavia recebem baixos salários e passam por intensificação na carga horária trabalhada. Portanto, há a necessidade de repensar políticas para organização do trabalho docente com valorização salarial dos profissionais e soluções de utilização do tempo para que os professores tenham mais acesso a cultura e ao lazer como meios de crescimento humano, profissional e social. 


\section{Considerações finais}

Nesta primeira década do século XXI, observamos uma presença mais efetiva do Estado no campo da educação escolar tanto no aspecto legal quanto nas ações de expansão da rede pública do ensino, notadamente na etapa da educação infantil, no ensino médio e técnico. Ao mesmo tempo em que houve avanço no setor público lainda que tímido, haja vista a dívida social), o setor privado também foi estimulado.

Todavia, a presença do Estado (na forma e no conteúdo) precisa ser explicada e relacionada com a perspectiva de desenvolvimento do Brasil para uma análise crítica sobre a função social da educação escolar no cenário pós-industrial. A rápida exposição aqui feita dos programas voltados para o ensino médio e profissional no país deixa observar que as correlações de forças estão acentuadas, o que faz apontarem para direções diversas e, geralmente, não-convergentes.

Não obstante os avanços legais e a implantação de programas educacionais voltados para a expansão do ensino médio e de suas modalidades, o resultado ainda é pífio, fazendo crer que a universalização do ensino para a população de 4 a 17 anos de idade e a garantia da oferta do ensino médio continuarão sendo desafios de longo prazo de superação enquanto a divisão do trabalho capitalista e os interesses privados dominarem a pauta política e social.

\section{Referências}

BARBOSA, Luiz; SOUZA, José. Política e economia no governo Lula. Rio de Janeiro: Contraponto, 2010. BECK, Ulrich. La sociedad del riesgo: hacia una nueva modernidad. Barcelona: Paidós Surcos, 2003. BRASIL. INSTITUTO BRASILEIRO DE GEOGRAFIA E ESTATísTICA (IBGE). Pesquisa Nacional por Amostra de Domicílios 2009. Brasília: IBGE, 2009.

BRASIL. MINISTÉRIO DA EDUCAÇÃO (MEC). Portaria n 971, de 09 de outubro de 2009. Diário Oficial da União, Brasília, 13 out. 2009. Seção 1, p. 52.

BRASIL, Conselho Nacional de Educação. Resolução CEB/CNE n 4 de 13 de julho de 2010. Diário Oficial da União, Brasília, 14 jul. 2010. Seção 1, p. 824.

BRASIL. INSTITUTO NACIONAL DE ESTUDOS E PESQUISAS EDUCACIONAIS ANÍSIO TEIXEIRA (INEP). Censo Escolar 2010. Brasília: INEP, 2010.

CURY, Carlos Roberto Jamil. A educação básica no Brasil. Educação \& Sociedade, Campinas, v. 23, n. 80, set. 2002.

BRASIL. Lei no 12.061, de 27 de outubro de 2009, que alterou o inciso II do art. $4^{\circ}$ e o inciso VI do art. 10 da Lei no 9.394/96, para assegurar o acesso de todos os interessados ao ensino médio público. Diário Oficial da União, Brasília, 28 out. 2009. Seção 1, p. 1. 
FERREIRA, Eliza Bartolozzi. A educação profissional nos PPAs dos governos FHC e Lula. Educação \& Realidade, Porto Alegre, v. 35, n. 1. Porto Alegre: URGS, jan/abr 2010.

.; POCHMANN, Marcio. Educação e juventude na sociedade pós-industrial. In: OLIVEIRA, Dalila Andrade e DUARTE, Adriana. Políticas públicas e educação: regulação e conhecimento. Belo Horizonte: Fino Traço, 2011. p. 239-260.

.; OLIVEIRA, Dalila Andrade (Org.). Crise da escola e políticas educativas. Belo Horizonte: Autêntica, 2009.

FILGUEIRAS, Luiz; GONÇALVES, Reinaldo. A economia política do governo Lula. Rio de Janeiro: Contraponto, 2007.

INSTITUTO DE PESQUISA ECONÔMICA APLICADA (IPEA). Comunicado nº 89: emprego e oferta de mão de obra qualificada no Brasil: projeções para 2011. Brasília: IPEA, 2011. Disponível em: < http://www.ipea.gov.br/portal/images/stories/PDFs/comunicado/110428_comunicadoipea89.pdf>. Acesso em: 04 dez. 2011.

INSTITUTO DE PESQUISA ECONÔMICA APLICADA (IPEA). Políticas Sociais: acompanhamento e análise: Vinte Anos da Constituição Federal. Boletins IPEA, Brasília, v. 2, n. 17, 2009.

KUENZER, Acácia. As relações entre trabalho e educação no regime de acumulação flexível: apontamentos para discutir categorias e políticas. In: REUNIÃO ANUAL DA ANPEd, 30., Caxambu, 2007. Anais... Caxambu: ANPEd, 2007.

0 ensino médio no plano nacional de educação 2011-2020: superando a década perdida? Educação \& Sociedade, Campinas, v. 31, n. 112, jul.-set. 2010.

OLIVEIRA, Dalila Andrade. 0 ensino médio diante da obrigatoriedade ampliada: que lições podemos tirar de experiências observadas? Revista Brasileira de Estudos Pedagógicos, Brasília, v. 91, n. 228, p. 269-290, maio-ago. 2010.

POCHMANN, Marcio. Desenvolvimento e perspectivas novas para o Brasil. São Paulo: Cortez, 2010. SOUZA, Sandra Zákia Lian; OLIVEIRA, Romualdo Portela de; LOPES, Valéria Virgínia. Ensino médio noturno: democratização e diversidade. Brasília: Ministério da Educação, Secretaria de Educação Básica, 2006. 140 p.

Recebido em agosto de 2011.

Aprovado em novembro de 2011.

Eliza Bartolozzi Ferreira, doutora em Educação pela UFMG. Professora do Centro de Educação e do Programa de Pós-Graduação em Educação da Universidade Federal do Espírito Santo. Desenvolve estudos e pesquisas na área de Educação com ênfase em Política Educacional, gestão escolar e planejamento na Educação Básica e profissional. É coordenadora do Núcleo de Estudos e Pesquisas em Políticas Educacionais (NEPE/UFES) e secretária adjunta da ANPEd. Últimas publicações: FERREIRA, Eliza Bartolozzi; FONSECA, Marilia. 0 planejamento das políticas educativas no Brasil e seus desafios atuais. Revista Perspectiva, Florianópolis, UFSC, v. 29, n. 1, p. 239-260. 2011. E-mail: eliza.bartolozzidgmail.com. 